\title{
Improved Ferroelectric and Leakage Properties of Ce Doped in $\mathrm{BiFeO}_{3}$ Thin Films
}

\author{
Alima Bai, Shifeng Zhao, and Jieyu Chen \\ School of Physical Science and Technology and Inner Mongolia Key Lab of Nanoscience and Nanotechnology, \\ Inner Mongolia University, Hohhot 010021, China \\ Correspondence should be addressed to Shifeng Zhao; zhsf@imu.edu.cn \\ Received 10 May 2014; Accepted 20 May 2014; Published 8 June 2014 \\ Academic Editor: Daniela Predoi \\ Copyright (C) 2014 Alima Bai et al. This is an open access article distributed under the Creative Commons Attribution License, \\ which permits unrestricted use, distribution, and reproduction in any medium, provided the original work is properly cited. \\ Ce doped $\mathrm{BiFeO}_{3}$ thin films with a perovskite structure were prepared using solution-gelation method. It shows that the ferroelectric \\ properties have been enhanced after doping Ce. The enhanced ferroelectric properties are attributed to the structural transformation \\ and the reduced leakage current after doping rare metal of Ce. It has been found that the phase structures of the films transfer from \\ rhombohedral symmetry structure to the coexistence of the tetragonal and orthorhombic symmetry structure. And $\mathrm{Fe}^{2+}$ ions have \\ been reduced, which leads to the decreased leakage for $\mathrm{Ce}$ doped $\mathrm{BiFeO}_{3}$ thin films. The present work can provide an available way \\ to improve the ferroelectric and leakage properties for multiferroic $\mathrm{BiFeO}_{3}$ based thin films.
}

\section{Introduction}

Multiferroic materials exhibit ferroelectric, ferromagnetic, and ferroelasticity properties simultaneously in a certain temperature range. The single phase $\mathrm{BiFeO}_{3}(\mathrm{BFO})$ materials with perovskite structure have aroused wide concerns due to its high curie temperature $\left(T_{N}\right)$ of $1103 \mathrm{~K}$ and Neil temperature $\left(T_{C}\right)$ of $643 \mathrm{~K}$ [1], which make it a most promising candidate in ferroelectric memory storage and magnetoelectric devices [2-5]. However, for $\mathrm{BiFeO}_{3}$ materials with a rhombohedrally distorted perovskite structure belonging to the space group $\mathrm{R} 3 \mathrm{c}$, it is difficult to gain a large saturation and remnant polarization due to the higher leakage current arising from defects such as impurity phases and oxygen vacancies $[6,7]$. Several investigations have been carried out to prove that it is an effective approach for rare earth iron doping at Bi site to overcome the technical barrier and improve the ferroelectric and leakage properties of $\mathrm{BiFeO}_{3}$ materials [8-10]. Evidently, donor and acceptor dopants have contrary effects on modulating the charged defects. Thus, it becomes necessary to further understand how they affect the respective polarity and polarization stability of $\mathrm{BiFeO}_{3}$ thin films. However, most of these studies were focused on ceramics and bulk materials $[11,12]$, which are not fit for the rapidly developing micro- and nanoelectromechanical system (MEMS\&NEMS).
Therefore, in this work, Ce doped $\mathrm{BiFeO}_{3}$ thin films were prepared using solution-gelation method as this technique can well control the stoichiometric ratio. Ce will replace $\mathrm{Bi}$ of A sites in perovskite structure of $\mathrm{ABO}_{3}$. The choice of the dopant ion was based on the fact that $\mathrm{Ce}^{3+}$ has a more stable electronic configuration than $\mathrm{Bi}^{3+}$, which minimizes the leakage current and further improves ferroelectric properties in $\mathrm{BiFeO}_{3}$ thin films. The origins of the improved ferroelectric and leakage properties are discussed in detail in this paper. The present work can provide an available way to improve the ferroelectric properties for single phase multiferroic $\mathrm{BiFeO}_{3}$ based thin films.

\section{Experiment}

The pure and $\mathrm{Ce}$ doped $\mathrm{BiFeO}_{3}$ thin films were prepared using the solution-gelation method. All the reactions were carried out at room temperature under ambient conditions. High-purity bismuth nitrate $\left[\mathrm{Bi}\left(\mathrm{NO}_{3}\right)_{3} \cdot 5 \mathrm{H}_{2} \mathrm{O}\right]$, ferric nitrate $\left[\mathrm{Fe}\left(\mathrm{NO}_{3}\right)_{3} \cdot 9 \mathrm{H}_{2} \mathrm{O}\right]$, and cerium nitrate $\left[\mathrm{Ce}\left(\mathrm{NO}_{3}\right)_{3} \cdot 6 \mathrm{H}_{2} \mathrm{O}\right]$ were obtained from commercial sources (Alfa Aesar); they were dissolved in solvent ethylene glycol monomethyl ether in proper proportions of $0.99: 1: 0.1$ and stirred until the solutions turn into transparent for about three to four hours. 


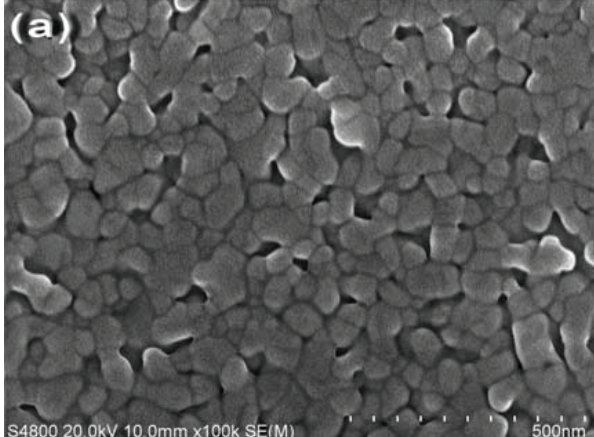

(a)

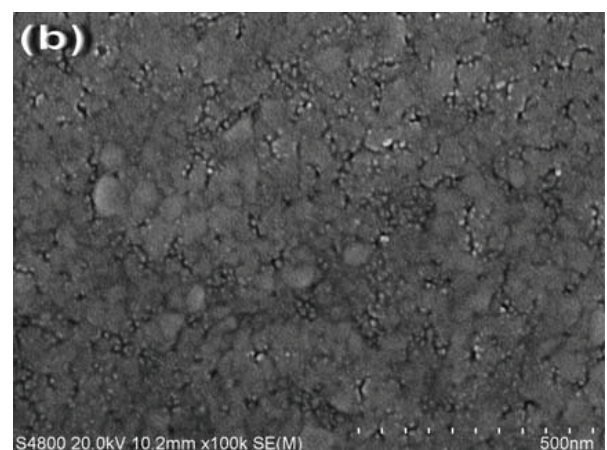

(b)

FIgure 1: The typical SEM images of the thin films, (a) pure $\mathrm{BiFeO}_{3}$ thin films, (b) Ce doped $\mathrm{BiFeO}_{3}$ thin films.

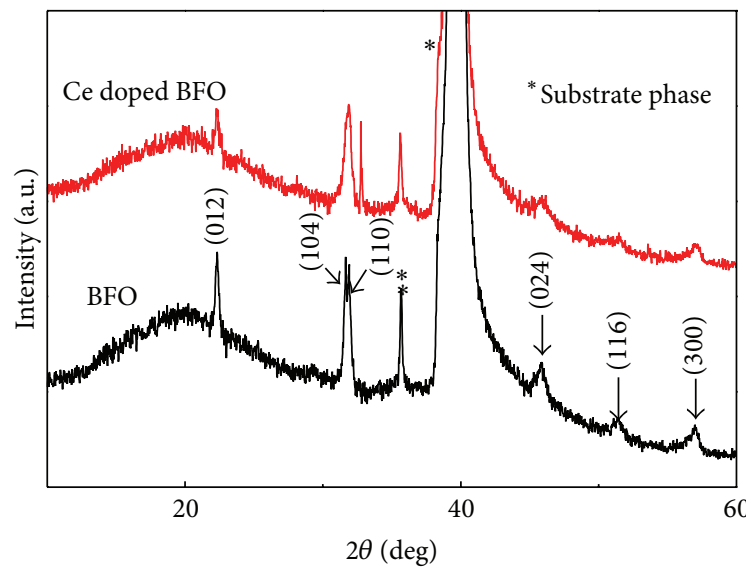

(a)

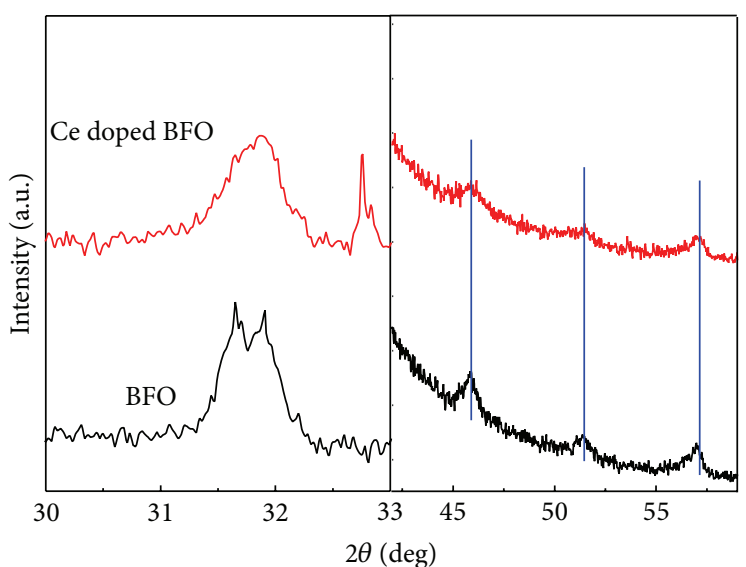

(b)

FIgURE 2: (a) XRD patterns of pure and Ce doped $\mathrm{BiFeO}_{3}$ thin films, (b) magnified XRD patterns.

$\left[\mathrm{Bi}\left(\mathrm{NO}_{3}\right)_{3} \cdot 5 \mathrm{H}_{2} \mathrm{O}\right]$ should be added by excessive $10 \%$ for volatilizing $\mathrm{Bi}$ in process of dissolving and annealing. The process of preparing pure $\mathrm{BiFeO}_{3}$ solution is similar to the above one, but $\left[\mathrm{Bi}\left(\mathrm{NO}_{3}\right)_{3} \cdot 5 \mathrm{H}_{2} \mathrm{O}\right]$ and $\left[\mathrm{Fe}\left(\mathrm{NO}_{3}\right)_{3} \cdot 9 \mathrm{H}_{2} \mathrm{O}\right]$ had the proportion of $1.1: 1$. Further, the prepared solutions were aged for several days. Then, the thin films were coated by spin coater. Here are conditions of rotation speed; low velocity is $400 \mathrm{r} / \mathrm{min}$ and high velocity is $3500 \mathrm{r} / \mathrm{min}$. Next thin films were baked on the heating stage for five minutes at $280^{\circ} \mathrm{C}$ and annealed with rapid thermal processor system for five minutes at $550^{\circ} \mathrm{C}$. This process was repeated twelve times and final annealing was for twenty minutes to obtain the $\mathrm{BiFeO}_{3}$ thin films with the thickness of $300 \mathrm{~nm}$. The orientation, crystal structure, and phase purity of the thin films were analyzed by X-ray diffraction (XRD, PanalyticalEmpyrean) with $\mathrm{Cu}-\mathrm{K} \alpha$ radiation $(\lambda=0.15406 \mathrm{~nm})$. The surface morphologies of the thin films were investigated by a scanning electron microscope (SEM, Hitachi S-4800). Raman spectroscopy measurements were performed at room temperature using a confocal Raman spectroscope (NT-MDT NTEGRA Spectra) with a $633 \mathrm{~nm}$ excitation laser with an initial power of $10 \mathrm{~mW}$. For the fabrication of $\mathrm{BiFeO}_{3}$ based multiferroic thin film capacitors, Au top electrodes with a diameter of $0.2 \mathrm{~mm}$ were deposited on the surface of the thin films using an ion sputtering method. The ferroelectric and leakage properties of the thin films capacitors were measured using a multiferroic tester system (MultiFerroic100V, Radient Technology, USA) at room temperature. The binding energies of atoms and orbits for the samples were characterized by Xray photoelectron spectroscopy (XPS, KRATOS-AMICUS). The cleaning treatments of thin films were carried out using Ar ion bombardment. And all binding energies were calibrated with respect to $\mathrm{C} 1 \mathrm{~s}$ spectral line at $284.8 \mathrm{eV}$.

\section{Results and Discussion}

The typical SEM images of the pure and $\mathrm{Ce}$ doped $\mathrm{BiFeO}_{3}$ thin films were shown in Figure 1. One can clearly observe that both thin films are assembled with uniformly distributed grains. Some small voids can be observed from the surface of the pure $\mathrm{BiFeO}_{3}$ thin films in Figure 1(a), while for Ce doped $\mathrm{BiFeO}_{3}$ thin films, it exhibits more dense morphology and less small holes than the pure $\mathrm{BiFeO}_{3}$ thin films as shown in Figure 1(b). That is, the microstructure of thin films becomes more compact, which leads to the reduced voids for thin films. Thus result is attributed to the fact that $\mathrm{Ce}$ is more 


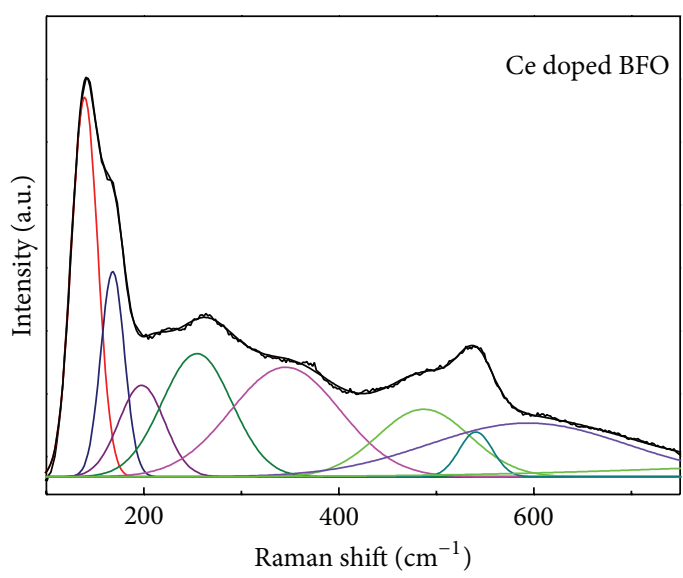

(a)

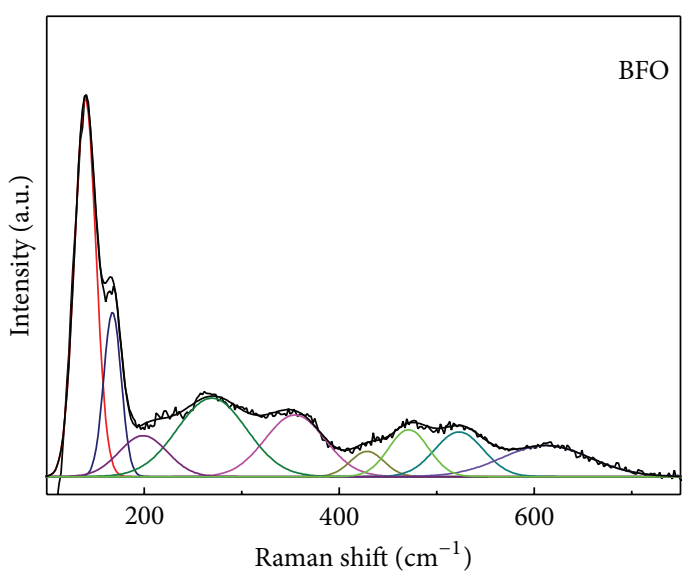

(b)

Figure 3: Raman scattering spectra of (a) Ce doped $\mathrm{BiFeO}_{3}$ and (b) pure $\mathrm{BiFeO}_{3}$ thin films.

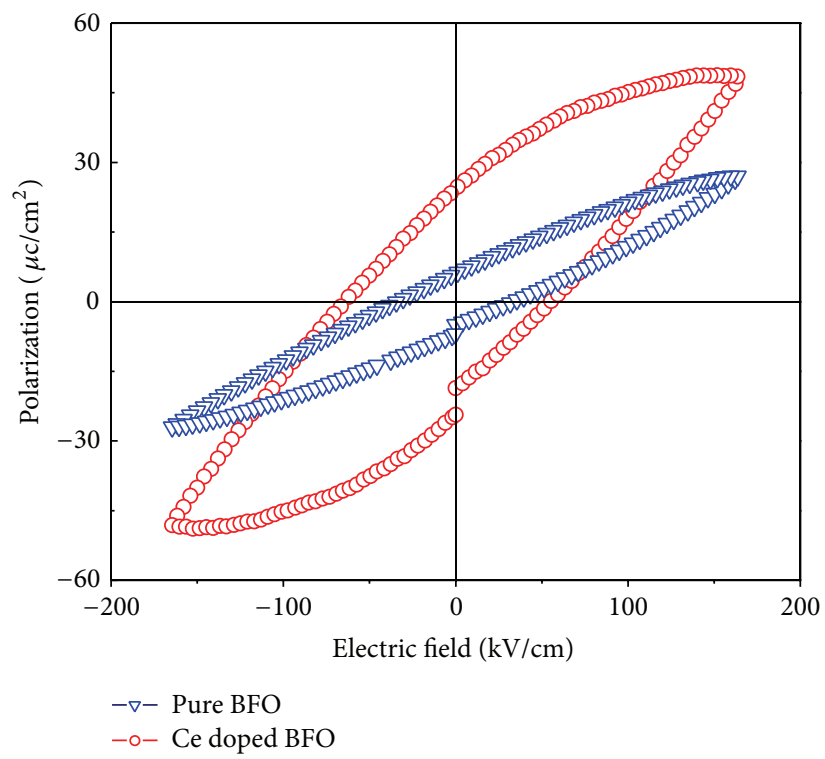

(a)

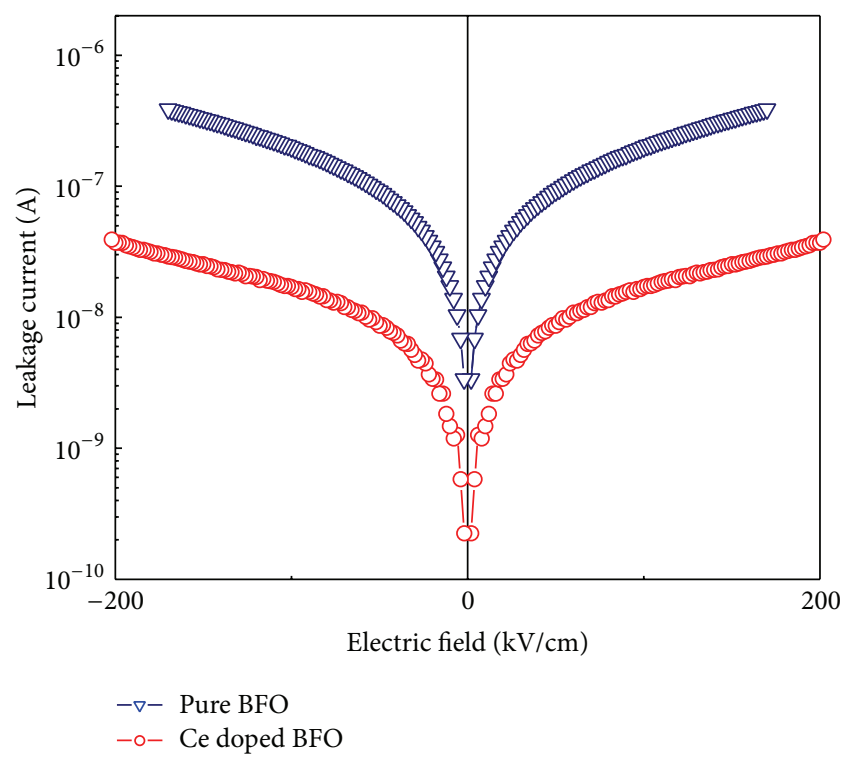

(b)

FIgURE 4: (a) Ferroelectric hysteresis of the pure and $\mathrm{Ce}$ doped $\mathrm{BiFeO}_{3}$ thin films, (b) leakage current curves of the pure and $\mathrm{Ce}$ doped $\mathrm{BiFeO}_{3}$ thin films.

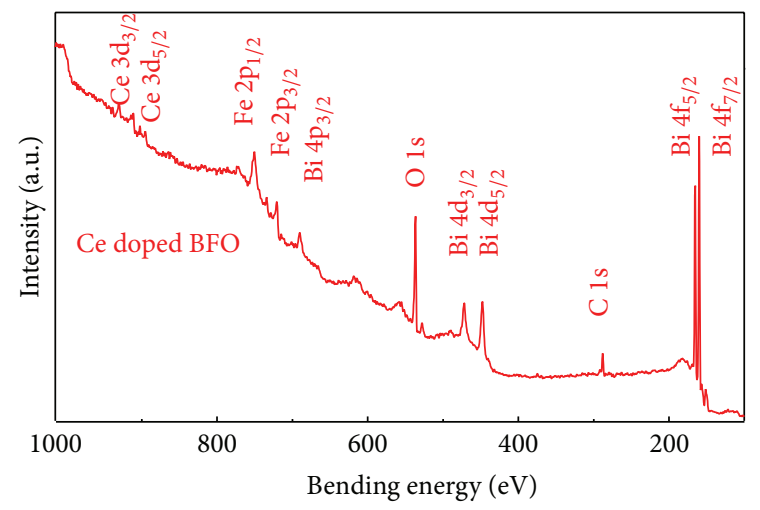

(a)

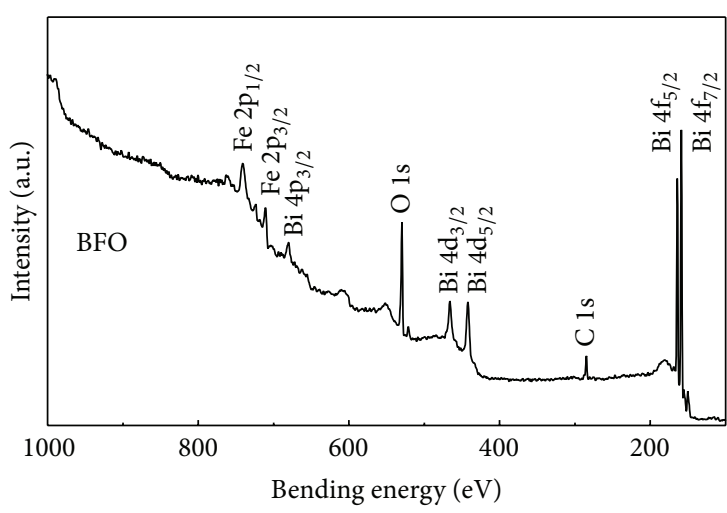

(b)

Figure 5: XPS survey spectra of pure and Ce doped $\mathrm{BiFeO}_{3}$ thin films. 


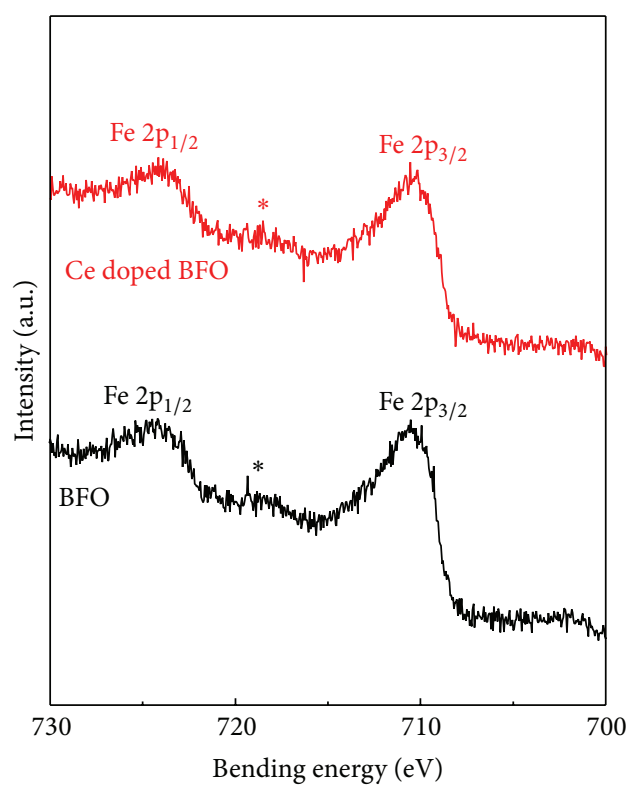

(a)

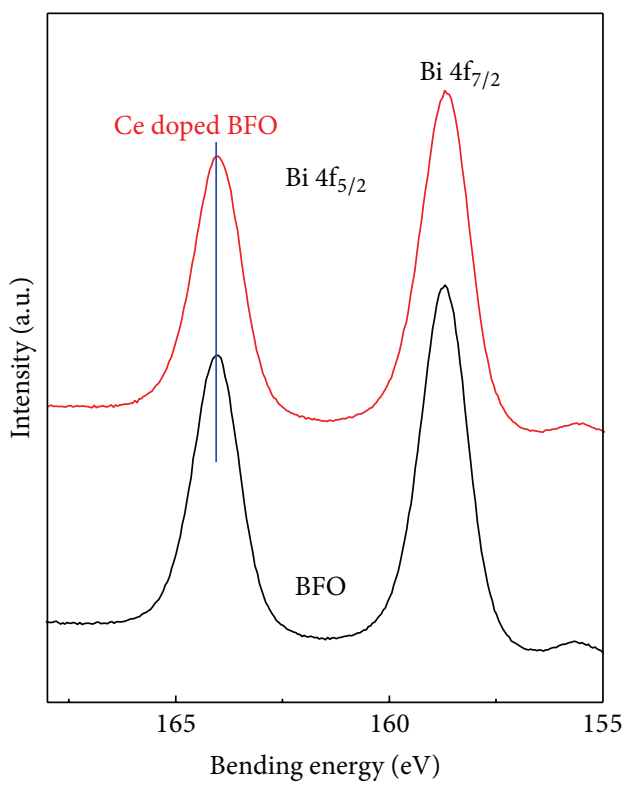

(c)

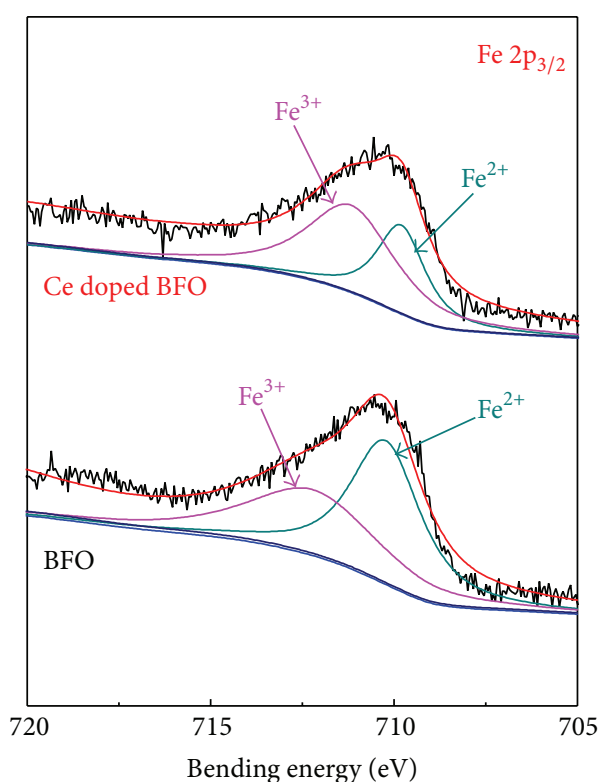

(b)

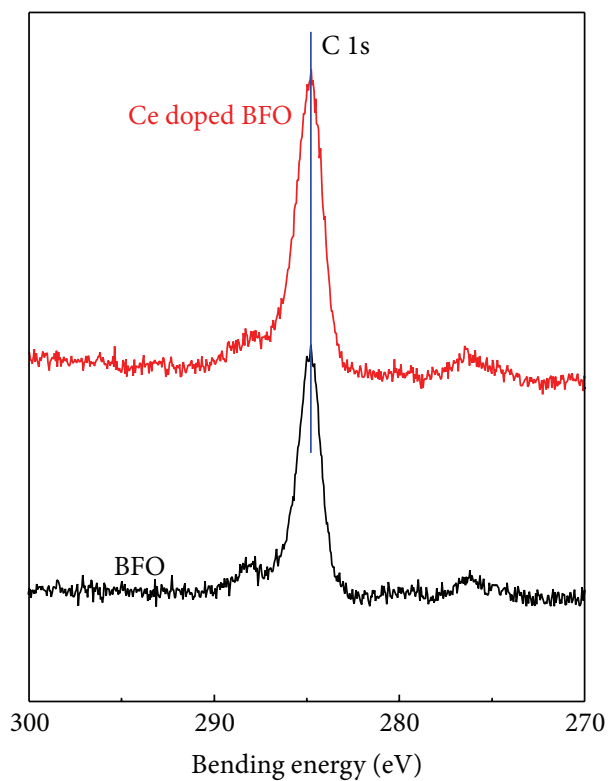

(d)

Figure 6: XPS patterns of the typical pure $\mathrm{BiFeO}_{3}$ and $\mathrm{Ce}$ doped $\mathrm{BiFeO}_{3}$ thin films. (a) High-resolution Fe 2p spectra, (b) fitting spectra of the $\mathrm{Fe} 2 \mathrm{p}_{3 / 2}$ peaks, (c) high-resolution Bi $4 \mathrm{f}$ spectra, and (d) figh-resolution $\mathrm{C}$ 1s spectra.

stable than Bi element, which reduces oxygen vacancy and increases the combining of elements. This compact surface morphology is available to improve the properties such as ferroelectricity and the leakage current of thin films.

Figure 2 presents the XRD patterns of the pure and Ce doped $\mathrm{BiFeO}_{3}$ thin films. It can be seen that the thin films are polycrystalline perovskite structure without any prominent impurity peaks (e.g., $\mathrm{Bi}_{2} \mathrm{Fe}_{4} \mathrm{O}_{9}, \mathrm{Bi}_{25} \mathrm{FeO}_{40}$, etc.) observed. The absence of the diffraction peaks of $\mathrm{Ce}$ and its oxides implies that $\mathrm{Ce}$ is incorporated with the $\mathrm{BiFeO}_{3}$ by the means of substitution for Bi. Figure 1(b) further gives an expanded view on the location of diffraction peaks in the range of $30-33$ and $47-57$ degree $(2 \theta)$. It shows clearly that the pure $\mathrm{BiFeO}_{3}$ thin film has a perovskite rhombohedral structure belonging to the space group $\mathrm{R} 3 \mathrm{c}$ as the (104) and (110) diffraction peaks are almost completely separated, while the two diffraction peaks were greatly overlapped to form one peak with the Ce substitution doping at $\mathrm{Bi}$ site, which indicates that the rhombohedral distortion is reduced toward the coexistence of tetragonal and orthorhombic symmetry structure after doping Ce. This structural transformation is consistent with the other reports on rare earth doped $\mathrm{BiFeO}_{3}$ ceramics $[13,14]$. Besides, it can be seen that the position of all the diffraction peaks does not 
TABLE 1: Raman scattering modes of the pure and Ce doped $\mathrm{BiFeO}_{3}$ thin films.

\begin{tabular}{lcc}
\hline Raman modes & $\mathrm{BiFeO}_{3}$ thin films & Ce doped $\mathrm{BiFeO}_{3}$ thin films \\
\hline $\mathrm{A}_{1}-1\left(\mathrm{~cm}^{-1}\right)$ & 141.10 & 139.06 \\
$\mathrm{~A}_{1}-2\left(\mathrm{~cm}^{-1}\right)$ & 167.88 & 167.35 \\
$\mathrm{~A}_{1}-3\left(\mathrm{~cm}^{-1}\right)$ & 198.66 & 197.66 \\
$\mathrm{E}-2\left(\mathrm{~cm}^{-1}\right)$ & 268.60 & 254.68 \\
$\mathrm{E}-5\left(\mathrm{~cm}^{-1}\right)$ & 355.53 & 346.64 \\
$\mathrm{~A}_{1}-4\left(\mathrm{~cm}^{-1}\right)$ & 428.25 & - \\
$\mathrm{E}-7\left(\mathrm{~cm}^{-1}\right)$ & 471.04 & 487.72 \\
$\mathrm{E}-8\left(\mathrm{~cm}^{-1}\right)$ & 523.04 & 541.48 \\
$\mathrm{E}-9\left(\mathrm{~cm}^{-1}\right)$ & 612.05 & 595.63 \\
\hline
\end{tabular}

obviously shift. That is attributed to the almost equal ionic radius of $\mathrm{Ce}^{3+}(1.02 \AA)$ compared with that of $\mathrm{Bi}^{3+}(1.03 \AA)$.

Figure 3 shows the Raman scattering spectra of the pure and $\mathrm{Ce}$ doped $\mathrm{BiFeO}_{3}$ thin films. Table 1 reveals the Raman scattering modes of pure $\mathrm{BiFeO}_{3}$ and $\mathrm{Ce}$ doped $\mathrm{BiFeO}_{3}$ thin films including $A_{1}-1, A_{1}-2, A_{1}-3, A_{1}-4, E-2, E-5,5 E-7, E-8$, and E-9 modes, respectively. The observed scattering modes were in close agreement with the irreducible representation: $\Gamma=$ $4 A_{1}+9 E[15,16]$. Combining Table 1 and Figure 3, we found that $A_{1}-1 A_{1}-2, E-2$, and $A_{1}-3$ modes have got red shift and the scattering peak at $428.25 \mathrm{~cm}^{-1}$ has disappeared after doping Ce. The reason for this phenomenon can be stated as the following two aspects: one is that the change of the interaction between atoms due to the heavier atom of Bi replaced by the lighter atom of Ce causes the change of the phonon frequencies after doping Ce; another reason is structural phase transformation from rhombohedral symmetry structure to the coexistence of tetragonal and orthorhombic symmetry structure after doping $\mathrm{Ce}$, which leads to the change in $\mathrm{Bi}-\mathrm{O}$ covalent bonds as the bond controls the $\mathrm{E}-1, \mathrm{~A}_{1}-1, \mathrm{~A}_{1}-2, \mathrm{~A}_{1}-3$, and E-2 modes.

Figure 4(a) illustrates ferroelectric hysteresis and leakage current of the pure and $\mathrm{Ce}$ doped $\mathrm{BiFeO}_{3}$ thin films, respectively. As shown in Figure 4(a), the ferroelectric properties change after doping Ce. For the pure $\mathrm{BiFeO}_{3}$ thin films, the ferroelectric properties are poor and unsaturated ferroelectric hysteresis is observed, while the polarization has been enhanced for the film of Ce doped $\mathrm{BiFeO}_{3}$ thin films, especially under large electric field. After doping $\mathrm{Ce}$, the remanent and saturation polarization have been increased from $6.22 \mu \mathrm{c} / \mathrm{cm}^{2}$ to $25.10 \mu \mathrm{c} / \mathrm{cm}^{2}$ and from $27.07 \mu \mathrm{c} / \mathrm{cm}^{2}$ to $49.22 \mu \mathrm{c} / \mathrm{cm}^{2}$, respectively. It is caused by the structural transformation from the R3c space group of rhombohedral structure of the pure $\mathrm{BiFeO}_{3}$ thin films to the $\mathrm{Pna}_{1}$ space group of orthorhombic structure of $\mathrm{Ce}$ doped $\mathrm{BiFeO}_{3}$ thin films. Moreover, the improvement of ferroelectricity is also closely related to the leakage current behavior as discussed below.

Figure 4(b) further shows the leakage current versus electric field $(E)$ characteristics plots recorded with a voltage step width of $0.1 \mathrm{~V}$ of the thin films capacitors. It shows that the leakage currents of $\mathrm{Ce}$ doped $\mathrm{BiFeO}_{3}$ thin films are decreased by one to two orders of magnitude in comparison with the pure $\mathrm{BiFeO}_{3}$ thin films. For the pure $\mathrm{BiFeO}_{3}$ thin films, a substantial number of oxygen vacancies and $\mathrm{Fe}^{2+}$ ion are created to compensate the positive charge deficiency caused by the vaporization of Bi [17]. They serve as donorlike trapping centers for electrons, which can be activated to be free for current conduction at the applied electric field, further leading to the higher leakage current in the pure $\mathrm{BiFeO}_{3}$ thin films [18], while the leakage current of $\mathrm{BiFeO}_{3}$ thin films was decreased after doping Ce, which is attributed to two factors. On one hand, the reduction of leakage current results from the structural transformation as discussed above. The leakage current of the pure $\mathrm{BiFeO}_{3}$ thin films is larger than that of Ce doped $\mathrm{BiFeO}_{3}$ thin films, which indicates the rhombohedral structure is closely related to the higher leakage current density. The coexistence structure of tetragonal and orthorhombic symmetry structure in $\mathrm{BiFeO}_{3}$ thin films is an important season to decrease the leakage current. On the other hand, the creation of oxygen vacancies and the presence of $\mathrm{Fe}^{2+}$ ion were suppressed as it is effective for Ce substitution doping to control the volatility of Bi atoms. Thus XPS investigations further confirm those points.

In order to intensify the oxidation of $\mathrm{Fe}$, oxygen vacancies, and the elements for the pure and $\mathrm{Ce}$ doped $\mathrm{BiFeO}_{3}$ thin films, XPS survey spectra are presented in Figure 5. It reveals the presence of $\mathrm{Bi}, \mathrm{Fe}, \mathrm{O}$, and $\mathrm{Ce}$ without any other trace impurities except for a small amount of carbon for Ce doped $\mathrm{BiFeO}_{3}$ thin films. This confirms the chemical compositions of the pure and $\mathrm{Ce}$ doped $\mathrm{BiFeO}_{3}$ thin films.

In order to further intensify the oxidation of $\mathrm{Fe}$, Figure 6(a) presents the representative Fe 2p XPS spectra of the pure and $\mathrm{Ce}$ doped $\mathrm{BiFeO}_{3}$ thin films. Two main XPS peaks for $\mathrm{Fe} 2 \mathrm{p}_{1 / 2}$ and $\mathrm{Fe} 2 \mathrm{p}_{3 / 2}$ were observed in both the pure and the $\mathrm{Ce}$ doped $\mathrm{BiFeO}_{3}$ thin films. Moreover, a satellite peak was also identified, which was considered to be characteristic of the oxidation state of Fe. Due to different d orbital electron configuration, during the relaxation of metal cations, $\mathrm{Fe}^{2+}$ and $\mathrm{Fe}^{3+}$ cations always show the satellite peaks with the gap of $6 \mathrm{eV}$ and $8 \mathrm{eV}$ above the Fe $2 \mathrm{p}_{3 / 2}$ peaks, respectively [19].

We further analyze the peak of the $\mathrm{Fe}_{2 \mathrm{p} 3 / 2}$ by LorentzianGaussian fitting, as shown in Figure 6(b). It suggests that $\mathrm{Fe}^{3+}$ and $\mathrm{Fe}^{2+}$ cations are coexistence in both the thin films and the binding energy changes after doping Ce. The $\mathrm{Fe}_{2 \mathrm{p} 3 / 2}$ peak position for the pure $\mathrm{BiFeO}_{3}$ thin films is confirmed at $710.30 \mathrm{eV}$ for $\mathrm{Fe}^{2+}$ cations and $712.49 \mathrm{eV}$ for $\mathrm{Fe}^{3+}$ ions, respectively, while the $\mathrm{Fe}_{2 \mathrm{p} 3 / 2}$ peak position for Ce doped $\mathrm{BiFeO}_{3}$ films is confirmed at $709.79 \mathrm{eV}$ for $\mathrm{Fe}^{2+}$ ions and $711.28 \mathrm{eV}$ for $\mathrm{Fe}^{3+}$ cations, respectively. It is easy to conclude that the binding energy between $\mathrm{Fe}$ and $\mathrm{O}$ decreases after doping rare earth metal of $\mathrm{Ce}$. The change in $\mathrm{Bi}-\mathrm{O}$ covalent bonds is attributed to the structural phase transformation from rhombohedral symmetry structure to the coexistence of tetragonal and orthorhombic symmetry structure, which is accordant with the results of the Raman shift spectra discussed above. At the same time, the binding energy between $\mathrm{Bi}$ and $\mathrm{O}$ does not change after doping $\mathrm{Ce}$, as shown in Figure 6(c). The peak position is confirmed at $164.02 \mathrm{eV}$ for $\mathrm{Bi} 4 \mathrm{f}_{5 / 2}$ and $158.68 \mathrm{eV}$ for $\mathrm{Bi} 4 \mathrm{f}_{7 / 2}$. Figure $6(\mathrm{~d})$ further presents the XPS peak of $\mathrm{C}$ for the pure and $\mathrm{Ce}$ doped $\mathrm{BiFeO}_{3}$ thin 
films, which suggests that the peak shifts above would come from the change of binding energy rather than the measure errors.

As we know, electron hops between $\mathrm{Fe}^{3+}$ cations and $\mathrm{Fe}^{2+}$ ions are accordant with charged compensated oxygen vacancies. More $\mathrm{Fe}^{2+}$ ions imply more oxygen vacancies, which would cause large leakage current and further decrease ferroelectric properties. Fortunately, the ratio of $\mathrm{Fe}^{2+}$ to $\mathrm{Fe}^{3+}$ cations changes from about $1: 1$ to $1: 2$ by calculating the area of peak. It obviously means that the concentration of the $\mathrm{Fe}^{2+}$ is decreased after doping Ce. Therefore, the Ce doping was helpful to reduce the $\mathrm{Fe}^{2+}$ ions concentration in $\mathrm{BiFeO}_{3}$ based thin films, which decrease their leakage currents and further improve ferroelectric properties.

\section{Conclusions}

In summary, the pure and $\mathrm{Ce}$ doped $\mathrm{BiFeO}_{3}$ thin films were prepared by solution-gelation process and their phase structures, ferroelectric properties, and leakage were systematically investigated. The enhanced ferroelectric properties have been obtained after doping Ce. Thus enhancement is attributed to the structural transformation from rhombohedral symmetry structure to coexistence of orthorhombic symmetry structure revealed by XRD measurements. At the same time, the leakage current decreases obviously, which originates from the change of the binding energy between $\mathrm{Fe}-\mathrm{O}$ increases and the decrease of the concentration of the $\mathrm{Fe}^{2+}$ after doping Ce. The present work provides an available way on enhancing ferroelectric properties and possible multifunctional applications for $\mathrm{BiFeO}_{3}$ based thin films.

\section{Conflict of Interests}

The authors declare that there is no conflict of interests regarding the publication of this paper.

\section{Acknowledgments}

This work was financially supported by National Key Projects for Basic Research of China (973 Projects) (Grant no. 2012CB626815), the National Natural Science Foundation of China (Grant nos. 11264026 and 10904065), the Program for Young Talents of Science and Technology in Universities of Inner Mongolia Autonomous Region (Grant no. NJYT-12B05), and Program of Higher-Level Talents of Inner Mongolia University (Grant no. 115109).

\section{References}

[1] D. Lebeugle, A. Mougin, M. Viret, D. Colson, and L. Ranno, "Electric field switching of the magnetic anisotropy of a ferromagnetic layer exchange coupled to the multiferroic compound $\mathrm{BiFeO}_{3}$," Physical Review Letters, vol. 103, no. 25, Article ID 257601, 2009.

[2] S. Mathews, R. Ramesh, T. Venkatesan, and J. Benedetto, "Ferroelectric field effect transistor based on epitaxial perovskite heterostructures," Science, vol. 276, no. 5310, pp. 238-240, 1997.
[3] C. Ederer and N. A. Spaldin, "Weak ferromagnetism and magnetoelectric coupling in bismuth ferrite," Physical Review B, vol. 71, no. 6, Article ID 060401, 2005.

[4] W. Eerenstein, N. D. Mathur, and J. F. Scott, "Multiferroic and magnetoelectric materials," Nature, vol. 442, no. 7104, pp. 759$765,2006$.

[5] D. Lee, S. M. Yang, T. H. Kim et al., "Multilevel data storage memory using deterministic polarization control," Advanced Materials, vol. 24, no. 3, pp. 402-406, 2012.

[6] M. S. Bernardo, T. Jardiel, M. Peiteado et al., "Intrinsic compositional inhomogeneities in bulk Ti-doped $\mathrm{BiFeO}_{3}$ : microstructure development and multiferroic properties," Chemistry of Materials, vol. 25, no. 9, pp. 1533-1541, 2013.

[7] H. Ke, W. Wang, Y. B. Wang et al., "Factors controlling purephase multiferroic $\mathrm{BiFeO}_{3}$ powders synthesized by chemical coprecipitation," Journal of Alloys and Compounds, vol. 509, no. 5, pp. 2192-2197, 2011.

[8] A. P. Chen, H. H. Zhou, Z. X. Bi et al., "A new class of room-temperature multiferroic thin films with bismuth-based supercell structure," Advanced Materials, vol. 25, no. 7, pp. 10281032, 2013.

[9] D. P. Dutta, B. P. Mandal, R. Naik, G. Lawes, and A. K. Tyagi, "Magnetic, ferroelectric, and magnetocapacitive properties of sonochemically synthesized Sc-doped $\mathrm{BiFeO}_{3}$ nanoparticles," The Journal of Physical Chemistry C, vol. 117, no. 5, pp. 23822389, 2013.

[10] N. Jeon, D. Rout, W. Kim, and S. J. L. Kang, "Enhanced multiferroic properties of single-phase $\mathrm{BiFeO}_{3}$ bulk ceramics by Ho doping," Applied Physics Letters, vol. 98, no. 7, Article ID 072901, 2011.

[11] J.-B. Li, G. H. Rao, Y. Xiao et al., "Structural evolution and physical properties of $\mathrm{Bi}_{1-x} \mathrm{Gd}_{x} \mathrm{FeO}_{3}$ ceramics," Acta Materialia, vol. 58, no. 10, pp. 3701-3708, 2010.

[12] G. L. Yuan, S. W. Or, J. M. Liu, and Z. G. Liu, "Structural transformation and ferroelectromagnetic behavior Structural transformation and ferroelectromagnetic behavior in singlephase $\mathrm{Bi}_{1-x} \mathrm{Nd}_{x} \mathrm{FeO}_{3}$ multiferroic ceramics," Applied Physics Letters, vol. 89, no. 5, Article ID 052905, 2006.

[13] X. Q. Zhang, Y. Sui, X. J. Wang, Y. Wang, and Z. Wang, "Effect of Eu substitution on the crystal structure and multiferroic properties of $\mathrm{BiFeO}_{3}$," Journal of Alloys and Compounds, vol. 507, no. 1, pp. 157-161, 2010.

[14] L. R. Luo, W. Wei, X. Y. Yuan, K. Shen, M. X. Xu, and Q. Y. Xu, "Multiferroic properties of Y-doped $\mathrm{BiFeO}_{3}$," Journal of Alloys and Compounds, vol. 540, pp. 36-38, 2012.

[15] M. K. Singh, H. M. Jang, S. Ryu, and M. H. Jo, "Polarized Raman scattering of multiferroic $\mathrm{BiFeO}_{3}$ epitaxial films with rhombohedral R3c symmetry," Applied Physics Letters, vol. 88, no. 4, Article ID 042907, 2006.

[16] V. A. Khomchenko, I. O. Troyanchuk, M. I. Kovetskaya, and J. A. Paixao, "Mn substitution-driven structural and magnetic phase evolution in $\mathrm{Bi}_{1-x} \mathrm{Sm}_{x} \mathrm{FeO}_{3}$ multiferroics," Journal of Applied Physics, vol. 111, no. 1, Article ID 014110, 2012.

[17] S. H. Jo, S. G. Lee, and S. H. Lee, "Structural and pyroelectric properties of sol-gel derived multiferroic BFO thin films," Materials Research Bulletin, vol. 47, no. 2, pp. 409-412, 2012.

[18] G. D. Hu, S. H. Fan, C. H. Yang, and W. B. Wu, "Low leakage current and enhanced ferroelectric properties of $\mathrm{Ti}$ and $\mathrm{Zn}$ 
codoped $\mathrm{BiFeO}_{3}$ thin film," Applied Physics Letters, vol. 92, no. 19, Article ID 192905, 2008.

[19] L. Bi, A. R. Taussig, H.-S. Kim et al., "Structural, magnetic, and optical properties of $\mathrm{BiFeO}_{3}$ and $\mathrm{Bi}_{2} \mathrm{FeMnO}_{6}$ epitaxial thin films: an experimental and first-principles study," Physical Review B, vol. 78, no. 10, Article ID 104106, 2008. 

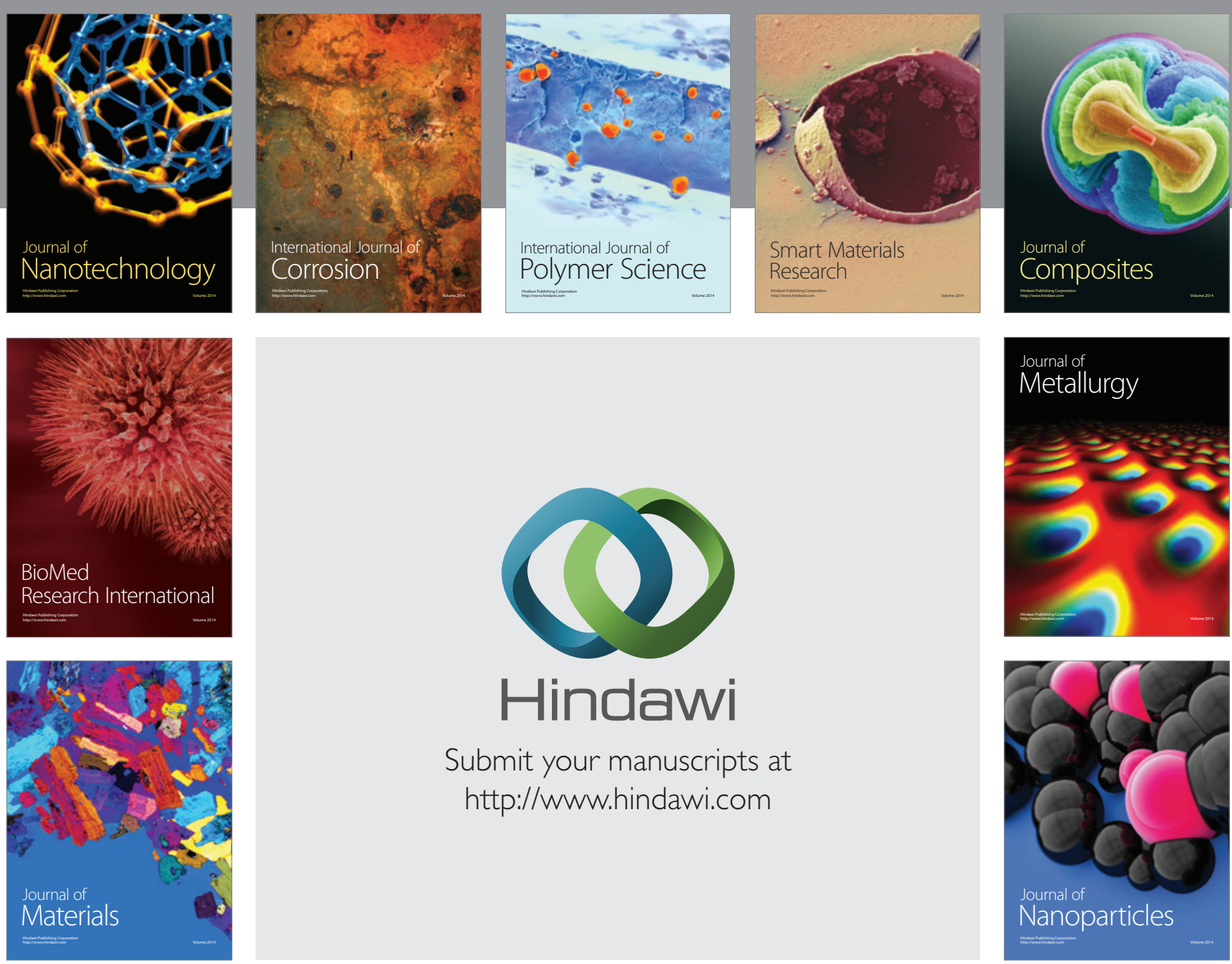

Submit your manuscripts at http://www.hindawi.com
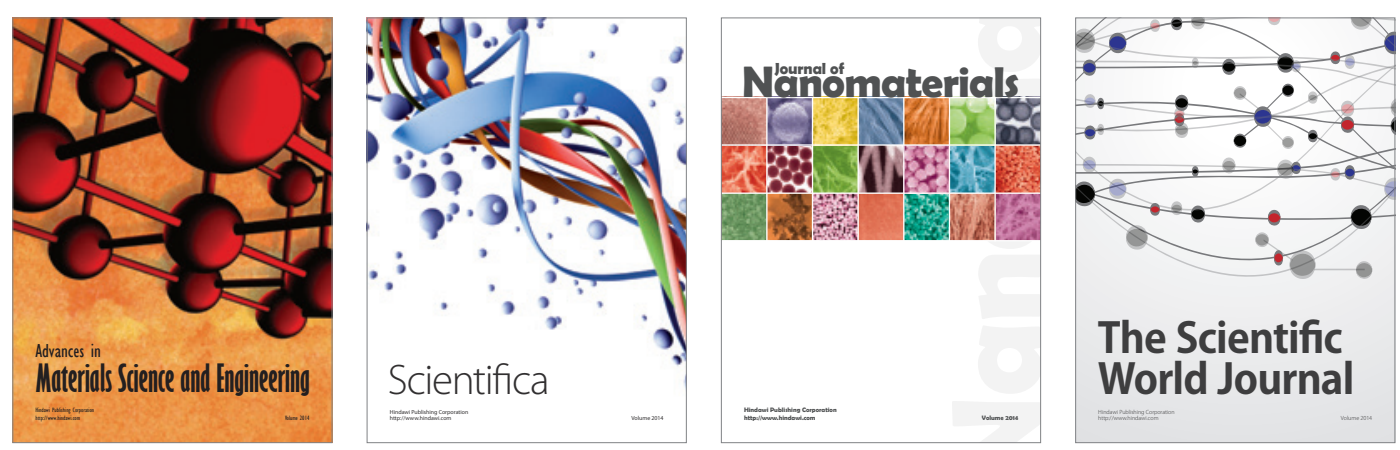

\section{The Scientific World Journal}
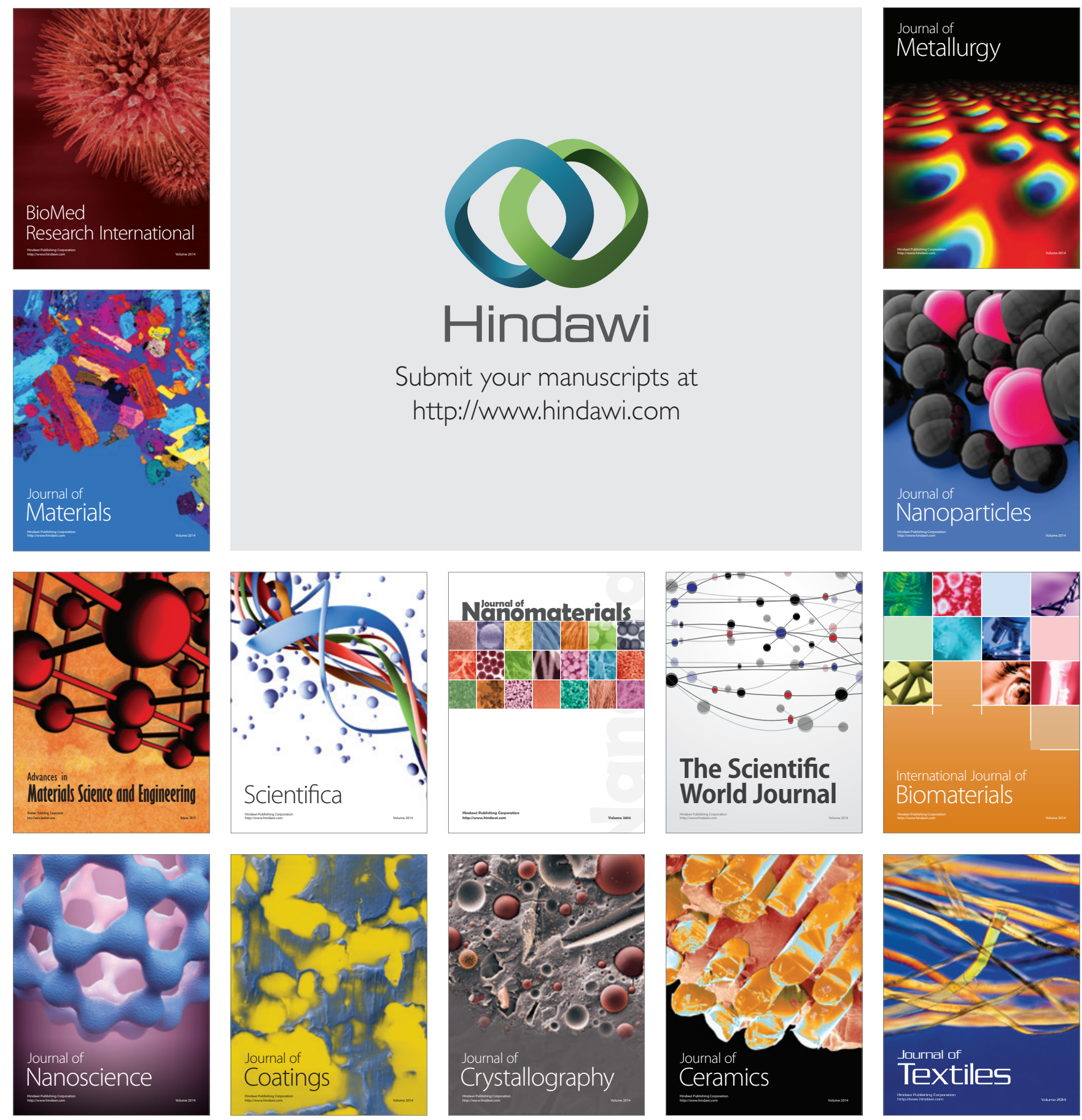